\title{
Fostering effective international collaboration for marine science in small island states
}

\begin{abstract}
Edward J. Hind 1*, Steven M. Alexander ${ }^{2}$, Stephanie J. Green ${ }^{3}$, Jacob P. Kritzer ${ }^{4}$, Michael J. Sweet ${ }^{5}$, Ayana Elizabeth Johnson ${ }^{6}$, Fabian P. Amargós ${ }^{7}$, Nicola S. Smith ${ }^{8}$ and Angelie M. Peterson ${ }^{9}$

${ }^{1}$ The Center for Marine Resource Studies, The School for Field Studies, South Caicos, Turks and Caicos Islands, ${ }^{2}$ Department of Environment and Resource Studies, University of Waterloo, Waterloo, ON, Canada, ${ }^{3}$ Department of Integrative Biology, Oregon State University, Corvallis, OR, USA, ${ }^{4}$ Environmental Defense Fund, Boston, MA, USA, ${ }^{5}$ Environmental Sustainability Research Centre, College of Life and Natural Sciences, University of Derby, Derby, UK, ${ }^{6}$ Waitt Institute, Washington, DC, USA, ${ }^{7}$ Centro de Investigaciones de Ecosistemas Costeros, Ciego de Ávila, Cuba, ${ }^{8}$ Department of Marine Resources, Ministry of Agriculture, Marine Resources and Local Government, Nassau, Bahamas, ${ }^{9}$ Centre for Resource Management and Environmental Studies, The University of the West Indies, St. Michael, Barbados
\end{abstract}

Keywords: small island states, marine scientists, collaborative research, research priorities, institutional capacity

\section{INTRODUCTION}

OPEN ACCESS

Edited by:

Murray A. Rudd,

Emory University, USA

Reviewed by:

Maria Beger,

The University of Queensland,

Australia

*Correspondence:

Edward J. Hind

e.hind@outlook.com

Specialty section:

This article was submitted to Global Change and the Future Ocean,

a section of the journal

Frontiers in Marine Science

Received: 21 July 2015 Accepted: 05 October 2015

Published: 21 October 2015

Citation:

Hind EJ, Alexander SM, Green SJ, Kritzer JP, Sweet MJ, Johnson AE, Amargós FP, Smith NS and

Peterson AM (2015) Fostering effective international collaboration for marine science in small island states. Front. Mar. Sci. 2:86.

doi: $10.3389 /$ fmars.2015.00086
Small island developing states (SIDS), termed also "large ocean states" (UN-OHRLLS, UNESCO, and UN-DOALOS, 2014) or simply "small island states" are highly dependent on ocean resources for livelihoods, food security, and culture (UNEP, UN DESA, and FAO, 2012; UNEP, 2014). These states are also disproportionately vulnerable to the increasing impacts of climate change, ocean acidification, overfishing, and other shocks to the marine environment ${ }^{2}$ (Newton et al., 2007; Alvarez-Filip et al., 2009; Paddack et al., 2009; House, 2013; UN, 2014). Subsequently, the blue economies and important ecosystem services their environments support (Jumeau, 2013; UN DESA, 2014) are compromised (UNEP, UN DESA, and FAO, 2012; UN-OHRLLS, UNESCO, and UN-DOALOS, 2014). This makes strong, adaptive, science-based management critical; however, marine science capacity has typically been significantly lower in these states than in larger coastal ones.

Small island states tend to have fewer, smaller, and less well-funded research institutions, yet are responsible for comparatively larger marine territories and face multiple management challenges (Mahon, 2006; Morrison et al., 2013). This heightened vulnerability and limited capacity led to an explicit and urgent call following the 3rd International Conference on Small Island Developing States (SIDS Conference, 2014) to improve the comprehensiveness of marine science in small island states, thus enabling data-based responses to environmental shocks (General Assembly resolution 69/15) ${ }^{3}$. Specifically, the call asked for a rapid response to marine environmental shocks, to be achieved at least partially through global cooperation and information-sharing.

Increased international collaboration has been proposed as the most promising near-term mechanism for these states to develop active and comprehensive marine science programs

\footnotetext{
$1_{\text {http://aosis.org }}$

${ }^{2}$ The vulnerability of small island states to environmental change became a focus of the United Nations (UN) International Year of Small Island Developing States in 2014 (General Assembly resolution 67/206).

${ }^{3}$ General Assembly resolution 69/15, SIDS Accelerated Modalities of Action (SAMOA) Pathway, A/RES/67/15 (14 November 2014). Available online at: http://www.un.org/ga/search/view_doc.asp?symbol=A/RES/69/15\&Lang=E (Accessed July 22, 2015).
} 
(Fanning et al., 2011; UN-OHRLLS, UNESCO, and UNDOALOS, 2014; General Assembly resolution 67/206 ${ }^{4}$ ). Such collaborations are currently underway through several regional initiatives (UN DESA, 2014; UN-OHRLLS, UNESCO, and UN-DOALOS, 2014) and numerous smaller scale partnerships between international and local researchers. However, barriers to effective multi-national and cross-disciplinary research in small island states persist, including restricted funding, institutional bureaucracy, limited timeframes for collaboration, initial lack of local knowledge on the part of foreign researchers, and differences in working practices (Ross and Smith, 1974; Mahon, 2006; McConney et al., 2007; Hastings et al., 2015).

The goal of our paper is to characterize challenges and offer potential solutions for structuring collaborative research that benefits conservation, based on our collective experience as foreign and local scientists conducting collaborative research in small island states. Specifically, we draw upon presentations by the authors and discussions amongst an international audience of marine scientists at a symposium of the 3rd International Marine Conservation Congress (IMCC3) around the question: "What does on-the-ground best practice look like for effectively coproducing cross-border marine research in small island states?" Our discussion builds on broad guidance of the UN's SAMOA Pathway (General Assembly resolution 69/15), an output of SIDS Conference 2014, and takes into account international statements on cross-border research integrity ${ }^{5}$. The IMCC3 symposium was predominantly attended by foreign scientists collaborating in small island states, so we primarily offer experience-based advice for applied researchers in this community. We do, however, include key information and actionable recommendations (see Table 1) for local research communities in small island states, and for funders. Recommendations are made in the following areas, identified through thematic analysis of symposium discussions: (1) aligning priorities; (2) building long-term relationships; (3) enhancing local capacity; and (4) sharing research products.

\section{FOCAL AREAS FOR INTERNATIONAL MARINE SCIENCE COLLABORATIONS}

\section{Aligning Priorities}

Well-meaning engagement from foreign marine scientists can have limited or even negative impact if it does not meet locally identified needs in small island states (Mahon and McConney, 2004). External research that does not account for the priorities of local scientists is less likely to be integrated into marine management (UN-OHRLLS, UNESCO, and UNDOALOS, 2014), and may even negatively impact marine conservation efforts if local researchers divert their own research time to accommodate low priority work. In contrast, engagement

\footnotetext{
${ }^{4}$ General Assembly resolution 67/206, International Year of Small Island Developing States, A/RES/67/206 (21 December 2012). Available online at: http://www.un.org/en/ga/search/view_doc.asp?symbol=A/RES/67/206 (Accessed July 19, 2015).

5 e.g., The Montreal Statement-Agreed at the 3rd World Conference on Research Integrity, this non-binding document sets out responsibilities for managing collaborations, collaborative relationships, and research outcomes.
}

will likely have great benefits if it helps meet a high profile need that local scientists could not meet themselves, or if it transfers knowledge they can use to independently address future high priority needs.

By understanding existing national research priorities, foreign researchers-in collaboration with local partners-can tailor their research to support those priorities. Complimentarily, local researchers have an opportunity to be selective about the international collaborations they enter into, thereby ensuring work with foreign researchers will support and accelerate progress toward meeting their research needs. Such alignment should not preclude foreign scientists from bringing new ideas for scientific priorities to small island states that may address key gaps. Bringing new ideas, however, will require additional effort and dialogue to build local buy-in. It is also important to note that support for the basic monitoring of ecosystems to inform fundamental day-to-day marine management is often needed, and should not be neglected for the sake of only pursuing the novel.

Funders have a central role to play regarding which ideas actually become research collaborations. They can augment local capacity by directing funding to foreign scientists who demonstrate both a commitment to full engagement with local partners, and a high aptitude for innovation. Funders can also provide oversight by requiring grantees to focus on answering widely supported research questions (e.g., Parsons, 2014; Rudd, 2014). These steps can ensure global marine conservation priorities are met at the same time as local ones.

Use of facilitation can be effective for identifying shared research priorities and highlighting capabilities among collaborating local and foreign scientists. For instance, strengths, weaknesses, opportunities, and threats (SWOT) analysis has been used to identify research capacity and technical/knowledge needs in Mauritius (Sauer and Rotsaert, 2011), as well as high priority areas of attention for Caribbean marine governance (Fanning et al., 2011), and potential new marine resource datasets in Bermuda (Atwood et al., 2009). Other potentially productive facilitation approaches include workshops with facilitators (e.g., Parsons, 2014) and the Delphi method (e.g., Moreno-Casbas et al., 2001). Funders could include priority alignment as a standard prerequisite, encouraging these kinds of facilitation as a part of putting a cross-border funding application together.

Early, open, and ongoing coordination amongst involved and affected parties (e.g., government agencies, research institutions, funders, communities, marine industries, etc.) is critical. If local and foreign researchers coordinate more closely during the research planning phase, we may see a rise in the amount of research that is scientifically novel, and that informs sound management of local resources (UN-OHRLLS, UNESCO, and UN-DOALOS, 2014). Ensuring alignment with local partners (e.g., government agencies, research institutions, NGOs) has the key added benefit of incorporating more local people (e.g., other researchers, marine resource managers, community members) and their valuable knowledge throughout the full duration of a project-research planning, execution, and results dissemination. 
TABLE 1 | Actionable recommendations for international marine science collaborations in small island states.

\section{ALIGNING PRIORITIES}

Foreign scientists:

- Assign formal project time to engagement and coordination with local scientists and institutions.

- Seek to minimize local scientists' engagement fatigue by avoiding vague and overly tentative proposals.

- Review previous and current project reports/plans of local and other foreign researchers to avoid duplication and build synergies.

Local scientists and local institutions:

- Attract foreign scientist collaborators by presenting research priorities/needs at regional conferences also attended by foreign scientists (e.g., Gulf and Caribbean Fisheries Institute Conference).

- Proactively approach NGOs, which are typically more flexible in what research they undertake.

Local institutions:

- Structure research permitting as an engagement mechanism.

- Develop and disseminate prioritized list of research needs.

Funders:

- Commit a percentage of available funds to research where the specific aim is to address local marine research priorities.

- Communicate with local institutions before funding calls, so that you can advertise as part of the call the local marine research priorities foreign researchers should be looking to address.

- Score "research need," "local and foreign alignment," and "collaboration with local entities" at least as highly as "scientific excellence" when reviewing funding applications.

\section{BUILDING LONG-TERM RELATIONSHIPS}

\section{All collaborators:}

- Seek formal memorandums of understanding (MoUs) to support collaboration and supplement informal verbal communication (see Supplementary Material for an example MoU template).

- Agree on publication and outreach plans in advance and as they evolve to avoid conflicts over output message.

Foreign scientists:

- Follow formal protocols (e.g., obtaining research permits), especially in small island states where informal relations are not the norm.

- Use multiple forms of communication (e.g., face-to-face, email, local press, and social media) to ensure broad engagement.

- Encourage participation of local stakeholders by integrating experiential knowledge of local scientists and non-scientists into research (UNEP, 2014).

- Endeavor to have broader outreach by building relationships with individual small island state nationals who command wide local respect.

- Be available to support marine management decision-making during and after the research (e.g., volunteer logistical and data-production support, put forward policy recommendations based on research results).

Foreign institutions and foreign research teams:

- Include social scientists as they are often absent in small island states and ecological and social challenges and systems are deeply intertwined (McConney et al., 2011).

Local institutions:

- Formalize a procedure for negotiating MoUs with foreign scientists. Foreign scientists typically have to meet funding body deadlines, so it is possible to foster better relations through maintaining a simple and timely process attractive to potential collaborators.

- Set clear guidelines and expectations for foreign scientists in regards to the frequency and type of communication expected on research design, execution, and communication of results.

Funders:

- Support the unglamorous but critical work of building and maintaining long-term science capacity and monitoring programs.

ENHANCING LOCAL CAPACITY

All collaborators:

- Co-design research, co-conduct fieldwork, co-author research outputs, and co-develop marine policy recommendations.

Foreign institutions:

- Support marine science training (e.g., scholarships, participation in workshops/courses) for local scientists and students.

Local institutions, where necessary with the support of foreign institutions:

- Satisfy the training and salary requirements of local scientists, to encourage them to remain working in small island states.

Foreign institutions and Funders:

- Fund the vital knowledge-sharing and networking activity of marine science conference attendance for local scientists (Morrison et al., 2013).

- Construct local facilities that can be used by local scientists.

Funders:

- Stipulate that costs allocated for travel funding, conference attendance, and career development be split between foreign and local scientists, better integrating local scientists into international research community.

- Promote balanced local-foreign collaborations by offering funding for local scientists to research or receive training overseas in the states of their foreign collaborators.

- Provide funding for local researchers to procure core scientific equipment that will enable them to work alongside foreign researchers on more equal footing.

SHARING RESEARCH PRODUCTS

Foreign scientists and local scientists

- Acknowledge all collaborators clearly within any outputs, especially scientific publications and conference presentations.

- Respond to all communications about outputs within a time period set out in a formal MoU.

- Assign formal project time for co-analysis of data. Data becomes more valuable when all collaborators fully comprehend it in raw and processed formats, and it is presented to policymakers in a timely fashion.

Foreign scientists:

- Assign formal project time to outreach.

- Ensure outputs include more than peer-reviewed papers. Distilled messages should be communicated in easy to understand formats. 


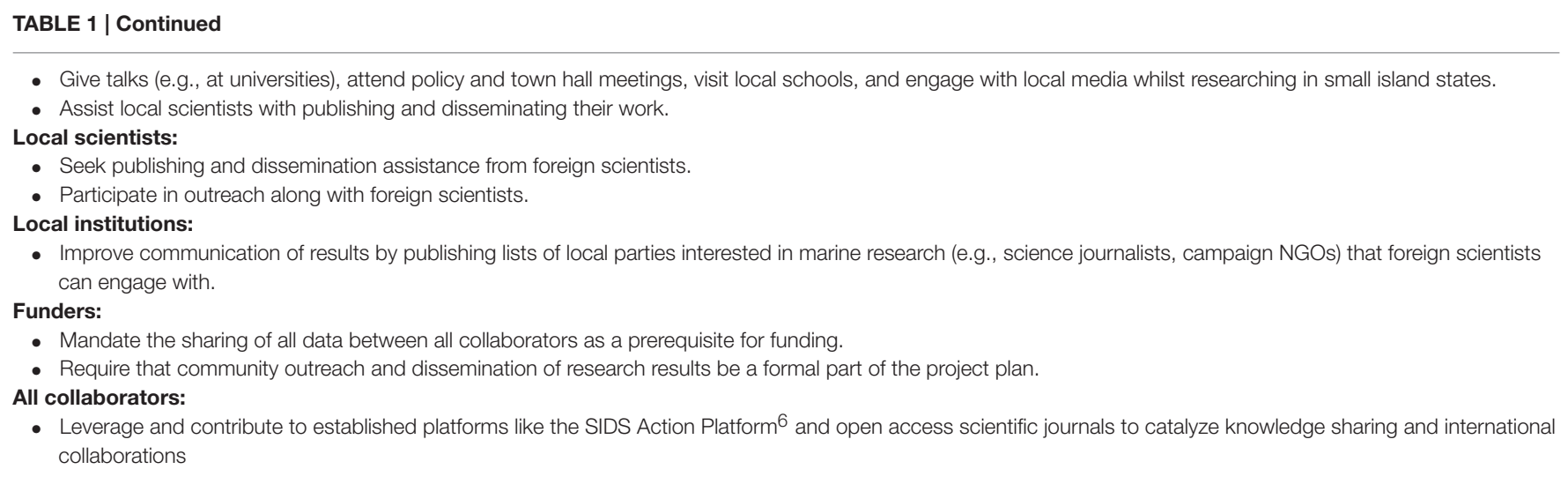

\section{Building Long-term Relationships}

Small island state policy-makers note long-term engagements are preferable for international marine science collaborations (UN-OHRLLS, UNESCO, and UN-DOALOS, 2014). Such lasting relationships also enable foreign marine scientists to build programs, long-term data sets, and a history of positive impact for their research groups. However, like all relationships, these must be thoughtfully cultivated. For example, maintaining these relationships requires foreign scientists give credit to local communities where it is due, ensuring that all research collaborations or research outputs, however large or small, are co-produced. The longevity of such collaborations is often strengthened when research alliances involve multiple stakeholders, especially non-scientists (e.g., fishers, women's groups).

In small island states, the most valuable engagement mechanisms (e.g., social networks) are often not in the public domain. Therefore, it is critical to the durability of multinational collaborations to foster personal relationships and social networks (McConney et al., 2011; Donovan et al., 2013). Prioritizing informal social networks is often less innate for foreign researchers accustomed to relying on strong bureaucratic linkages to transfer scientific knowledge into the hands of decision-makers. However, use of informal networks can be essential due to high staff turnover rates in many small island state scientific institutions (Mahon and McConney, 2004) and among foreign scientists with short contracts or grants. Accessing research and policy networks can be particularly challenging for foreign early career researchers. This can be addressed by working through or in association with established programs. For instance, the Fulbright Program ${ }^{7}$ has partnered students from the USA with mentor scientists in small island states who help them integrate into local networks.

When informal professional relationships-i.e., those unbound by formal agreements-break down, research collaborations often dissolve with them. These relationships are particularly fragile where they are primarily one-sided and/or there is a lack of communication, leaving colleagues not well informed or engaged. To avoid these pitfalls, cross-border

\footnotetext{
${ }^{6}$ www.sids2014.org

${ }^{7} \mathrm{http}$ //eca.state.gov/fulbright
}

research in small island states is best approached as a partnership (UNEP, 2014); foreign scientists can foster partnerships by always maintaining an open and collaborative approach. When such an approach is taken, researching side-by-side can increase bidirectional learning, foster transparency, build local capacity, and increase the likelihood that research results will be transmitted to influence policy (Binka, 2005). For example, sustained investment in relationship building by a foreign research institute in the Turks and Caicos Islands, precipitated a formal and collaboratively negotiated 5 year research plan where data collected was used by the national department charged with marine management (Wilson and Mills, 2008).

Building continuity through establishing long-term relationships develops the familiarity needed to develop communication strategies that break down barriers to sharing research resources and ideas in an informal setting (Mahon, 2006). By learning the colonial institutional structures so often present within many small island state policy and science communities, foreign scientists will better understand when fragmentation in the local institutional landscape requires communication with multiple actors (Donovan et al., 2013).

Funding agencies can further foster productive long-term collaborative relationships by following advice to put less value on short-term outputs (Weeks et al., 2014), structuring funding so that it can be dispersed in stages (e.g., for project scoping, during project, and post-project) like with the UK-dispersed Darwin Initiative funding 8 . While not glamorous, funding the process of building and maintaining long-term science capacity and monitoring programs is critical work.

\section{Enhancing Local Capacity}

Policy-makers hope marine science needs in small island states can eventually be met by regional self-sufficiency (e.g., interCaribbean collaboration), with foreign entities providing the majority of funding, training, and technology to transition to this target (Mahon, 2006; Fanning et al., 2011; Morrison et al., 2013). For foreign scientists, it is important to understand existing marine science capacity in these states when establishing research partnerships, and plan to build on, not duplicate it. It is therefore usually preferable to focus on strengthening existing

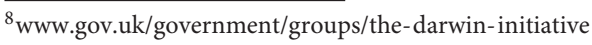


local research communities (McConney et al., 2011; Morrison et al., 2013), as has been the successful approach in Cuba where foreign NGOs are financing and equipping existing local marine research institutions (Goode, 2015).

Where funding is required to sustain collaborations, small island states are rarely in a position to provide capital, but often make valuable in-kind contributions. The onus to provide funding almost always rests with foreign scientists and their institutions. Therefore, capacity enhancement should focus on efforts that can continue once foreign assistance is absent. Limited funds may be better expended on sustaining lessdetailed, but sufficient longitudinal data gathering rather than on more detailed and expensive snapshot studies that meet local scientific needs only on a short-term basis (Mahon and McConney, 2004). For example, in the Solomon Islands, an environmental NGO from the United States developed a webbased application in collaboration with local researchers to continually collect landing data from fish markets via mobile telephones (Nyberg, 2014). Funders can also structure funding so that the enhancement of local capacity is weighted the same, or as more important, than the actual conducting of science. A fellowship offered by a UK NGO achieves this through assigning local early career researchers, including those from small island states, a senior scientist from the UK as a mentor ${ }^{9}$.

A common mistake of foreign scientists is not understanding the impacts that differences in capacities and resources between the scientific communities within their home territories and those they engage with in small island states have on research collaborations (McConney et al., 2007; Hastings et al., 2015). Restrictions on access to resources and technologies by local vs. foreign researchers can alienate or exclude local scientists. This can be something as fundamental as reliable electricity and Internet access, or even access to a computer outside of the office. Additionally, it is important to be mindful that small island states will unlikely be able to sustain large scientific institutions or expensive technologies in the long-term (Donovan et al., 2013). Funder support for procuring basic core scientific equipment (e.g., SCUBA gear, computers, digital voice recorders, cameras, water quality monitoring equipment) can dramatically increase local capacity for a small investment.

Foreign support of training efforts can pay exponential dividends. In the Bahamas, as part of a UN funded project, United States and Canadian scientists trained local scientists in survey techniques so that they could take part in collaborative monitoring of invasive lionfish (The Tribune, 2012). The Bahamian scientists have since used the skills they acquired during this training on different projects. Training non-scientists as citizen scientists is another approach that has enhanced coastal data-collecting capacity in small island states (e.g., UN-OHRLLS, UNESCO, and UN-DOALOS, 2014). This type of approach has the added benefit of future payoffs as it primarily engages youths with decades of potential data gathering ahead of them. Working with local schools to get marine science into the classroom can also be valuable in inspiring the next generation of local marine scientists. More generally, seeking enthusiastic, energetic local

${ }^{9}$ www.youtube.com/watch?v=Xkba_NG0dGs collaborators is an important consideration for foreign scientists, as these individuals are perhaps more likely to sustain scientific programs when external support ceases.

\section{Sharing Research Products}

There is increasing urgency for research on how to improve socio-ecological conditions in small island states (e.g., ecological resilience, human well-being). However, translating scientific discoveries into policy and practice requires going beyond conducting research, to identifying wider audiences with whom to share the results so that the data does not languish. For example, after research is complete, it is scientifically and ethically desirable to share both raw and processed data. Progress toward sound resource management and improved socio-ecological conditions can be prevented if data and results from research are not freely available (Tenopir et al., 2011). Creation of a central database for depositing all marine research data from small island states would be an important step.

Outreach aimed at policy-makers, local scientists, and nonscientist stakeholders is currently, and should continue to be, a requisite part of conducting any form of marine research in small island states (Mahon and McConney, 2004). The Australianbased team behind the Catlin Seaview Survey ${ }^{10}$ has provided one comprehensive model. From their underwater visual surveys of coral reefs in countries like the Maldives, Bermuda, and several in the Caribbean they have created a free-to-use database of reef health for scientists, educational materials for school children, and interactive imagery that enables the general public to take virtual dives.

Guidance from local colleagues is key in helping foreign scientists identify which of their outputs is most relevant to local audiences. Outreach, therefore, works best as an alliance activity with local and foreign scientists disseminating information alongside each other (Donovan et al., 2013). When conducted at each stage of research, clear, and consistent communication builds and sustains trust between foreigners and local communities, and incorporating feedback can refine the research focus and approach. Investment in outreach increases the likelihood that research findings on ecological status, trends, and shocks will inform marine management in a timely manner.

\section{TOWARD A FUTURE OF EFFECTIVE COLLABORATIONS}

Co-production of science, where the onus of fostering collaboration lies primarily with foreign researchers, is a preferable ethos for underpinning the development of best practices surrounding the issues discussed in this paper. When foreign scientists use only the research approaches typically implemented in their own states this can be seen as "intellectual colonialism" (Donovan et al., 2013) and can cause collaborations in small island states to break down, often with no meaningful output achieved.

\footnotetext{
${ }^{10} \mathrm{http}: / /$ catlinseaviewsurvey.com/
} 
A key element of aligned, long-term scientific collaboration is simply the right people finding each other. At SIDS Conference 2014 it was proposed that a platform be developed to connect seekers and providers of funding. A similar database linking seekers of marine science expertise (i.e., small island state institutions) with those wanting to apply their marine science expertise in small island states (i.e., foreign scientists) would also permit international marine science collaborations in small island states to be founded on mutual terms, aligning priorities at the very beginning.

In the face of the disproportionate burden of rapidly degrading and increasingly threatened marine resources, and imminent impacts (e.g., on food security, livelihoods, and ecological health) of environmental change to small island states, there is a need to move beyond a trial-and-error approach to collaborative research between local and foreign scientists. Our collective experiences suggest that when research priorities are aligned, long-term relationships are established, local capacity is enhanced, and research products are well communicated, international collaborations are more likely to be successful, resulting in improved ocean conservation and marine resource management in small island states (see also Hastings et al., 2015). We (the authors) have experienced successful collaborations with numerous small island states throughout the world, learned lessons from less successful ones, and hope that the suggestions put forward here will aid those interested in developing and nurturing effective collaborative partnerships.

\section{AUTHOR CONTRIBUTIONS}

Conceived symposium: EH, SA, and AP. Organized symposium: $\mathrm{EH}$ and SA. Presented and sat on panel at symposium: EH, JK, MS, and SG. Had input into symposium presentations: FA and NS. Took part in online discussions planning symposium, and then summarizing and interpreting its outputs: EH, SA, AP, JK, MS, SG, AJ, FA, and NS. Wrote paper: EH, SA, AP, JK, MS, SG,

\section{REFERENCES}

Alvarez-Filip, L., Dulvy, N. K., Gill, J. A., Côté, I. M., and Watkinson, A. R. (2009). Flattening of Caribbean coral reefs: region-wide declines in architectural complexity. Proc. Biol. Sci. 276, 3019-3025. doi: 10.1098/rspb. 2009.0339

Atwood, D., Mayall, K., and Ryerson, R. (2009). "Towards cooperative SDI in small island nations: the experience in Bermuda," in Proceedings for the American Society for Photogrammetry Annual Conference (Baltimore, MD). Available online at: http://www.asprs.org/a/publications/proceedings/baltimore09/0010. pdf (Accessed September 7, 2015).

Binka, F. (2005). North-South research collaborations: a move towards a true partnership? Trop. Med. Int. Health 10, 207-209. doi: 10.1111/j.13653156.2004.01373.x

Donovan, A. R., Bravo, M., and Oppenheimer, C. (2013). Co-production of an institution: Montserrat Volcano Observatory and social dependence on science. Sci. Publ. Policy 40, 171-186. doi: 10.1093/scipol/scs078

Fanning, L., Anderson, W., Bianchi, G., Clerveaux, W., Fournier, R., Haughton, M., et al. (2011). "Developing the vision for EBM governance in the Wider Caribbean," in Towards Marine Ecosystem-Based Management in the Wider
AJ, FA, and NS. Final approval of manuscript: EH, SA, AP, JK, MS, SG, AJ, FA, and NS.

\section{FUNDING}

EH gratefully acknowledges the key financial and logistical support provided by The School for Field Studies (SFS) Center for Marine Resource Studies. SA was supported by the Social Sciences and Humanities Research Council of Canada (SSHRC) and the International Development Research Centre (IDRC) through the Partnership for Canada-Caribbean Community Climate Change Adaptation, as well as through individual grants. SG was supported by the David H. Smith Conservation Research Program through the Society for Conservation Biology (SCB). Work in Cuba by JK and colleagues at EDF has been supported by the MacArthur Foundation, Ford Foundation, Christopher Reynolds Foundation and Waitt Foundation. The authors would like to acknowledge the support of the Environmental Sustainability Research Centre, University of Derby in the publishing of this paper.

\section{ACKNOWLEDGMENTS}

The authors are grateful to the organizers of the $3 r d$ International Marine Conservation Congress for allowing them to host the symposium on which this paper is based, and to the symposium attendees for their valuable inputs. They are particularly grateful to Sophia Wassermann for her assistance with recording the symposium outputs. Thanks is also due to Murray A. Rudd and Maria Beger, whose advice during peer-review substantially improved this manuscript.

\section{SUPPLEMENTARY MATERIAL}

The Supplementary Material for this article can be found online at: http://journal.frontiersin.org/article/10.3389/fmars. 2015.00086

Caribbean, eds L. Fanning, R. Mahon, and P. McConney (Amsterdam: Amsterdam University Press), 355-366.

Goode, E. (2015, July 13). Crown jewel of Cuba's coral reefs. New York Times. Available online at: http://www.nytimes.com/2015/07/14/science/crownjewel-of-cubas-coral-reefs.html?_r=1 (Accessed September 9, 2015).

Hastings, J. G., Orbach, M. K., Karrer, L. B., and Kaufman, L. (2015). Lessons learned from the Marine Management Area Science Program: insights for global conservation science programs. Coast. Manage. 43, 189-216. doi: 10.1080/08920753.2015.1005538

House, W. J. (2013). "Population and sustainable development in small island developing states: challenges, progress made and outstanding issues," in UN DESA Population Division, Technical Paper No. 2013/4 (New York, NY). Available online at: http://www.un.org/en/development/desa/population/ publications/pdf/technical/TP2013-4.pdf (Accessed July 16, 2015).

Jumeau, R. (2013). "Small island developing states, large ocean states," in Expert Group Meeting on Oceans, Seas and Sustainable Development: Implementation and follow-up to Rio+20, United Nations Headquarters, 18-19 April 2013. Available online at: https://sustainabledevelopment.un.org/content/documents/1772Ambassador\% 20Jumeau_EGM\%20Oceans\%20FINAL.pdf (Accessed July 16, 2015). 
Mahon, R. (2006). On the role of consulting in fisheries development. Mar. Policy 30, 593-595. doi: 10.1016/j.marpol.2005.09.002

Mahon, R., and McConney, P. (2004). Managing the managers: improving the structure and operation of fisheries departments in SIDS. Ocean Coast. Manage. 47, 529-535. doi: 10.1016/j.ocecoaman.2004.09.001

McConney, P., Mahon, R., Parsram, K., and Cox, S. A. (2011). "Fisheries networks in the Caribbean," in World Small Scale Fisheries - Contemporary Visions, ed R. Chuenpagdee (Delft: Eburon Academic Publishers), 273-284.

McConney, P., Oxenford, H. A., and Haughton, M. (2007). Management in the Gulf and Caribbean: mosaic or melting point? Gulf Caribb. Res. 19, 103-112. doi: $10.18785 /$ gcr.1902.13

Moreno-Casbas, T., Martín-Arribas, C., Orts-Cortés, I., and Comet-Cortés, P. (2001). Identification of priorities for nursing research in Spain: a Delphi study. J. Adv. Nurs. 35, 857-863. doi: 10.1046/j.1365-2648.2001. 01923.x

Morrison, R. J., Zhang, J., Urban, E. R., Hall, J., Ittekkot, V., Avril, B., et al. (2013). Developing human capital for successful implementation of international marine scientific research projects. Mar. Pollut. Bull. 77, 11-22. doi: 10.1016/j.marpolbul.2013.09.001

Newton, K., Côté, I. M., Pilling, G. M., Jennings, S., and Dulvy, N. K. (2007). Current and future sustainability of island coral reef fisheries. Curr. Biol. 17, 655-658. doi: 10.1016/j.cub.2007.02.054

Nyberg, R. (2014). Mobile Device Fisheries Program in Solomons Wins USAID Science and Technology Prize. Available online at: http://www.usaid.gov/asiaregional/press-releases/jan-29-2014-mobile-device-fisheries-program-solomons -wins-usaid-prize (Accessed September 9, 2015)

Paddack, M. J., Reynolds, J. D., Aguilar, C., Appeldoorn, R. S., Beets, J., Burkett, E. W., et al. (2009). Recent region-wide declines in Caribbean reef fish abundance. Curr. Biol. 19, 590-595. doi: 10.1016/j.cub.2009.02.041

Parsons, E. C. M., Favaro, B., Aguirre, A. A., Bauer, A. L., Blight, L. K., Cigliano, J. A., et al. (2014). Seventy-one important questions for the conservation of marine biodiversity. Conserv. Biol. 28, 1206-1214. doi: 10.1111/cobi. 12303

Ross, D. A., and Smith, L. J. (1974). Training and technical assistance in marine science - a viable transfer product. Ocean Dev. Int. Law 2, 219-253. doi: $10.1080 / 00908327409545549$

Rudd, M. A. (2014). Scientists' perspectives on global ocean research priorities. Front. Mar. Sci. 1:36. doi: 10.3389/fmars.2014.00036

Sauer, W., and Rotsaert, E. (2011). Revitalization of Fisheries Research in Mauritius. Smartfish Report SF/2011/22. Available online at: http://www.fao.org/3/aaz392e.pdf (Accessed 7 September, 2015).

The Tribune (2012, January 23). Expert title for lionfish project workers. The Tribune, 11.

Tenopir, C., Allard, S., Douglass, K., Aydinoglu, A. U., Wu, L., Read, E., et al. (2011). Data sharing by scientists: practices and perceptions. PLoS ONE 6:e21101. doi: 10.1371/journal.pone.0021101
UN (2014). Trends in Sustainable Development - Small Island Developing States (SIDS) Report. New York, NY: United Nations. Available online at: http://www.un.org/en/development/desa/publications/trends-in-sustainabledevelopment-small-island-developing-states-sids.html (Accessed July 16, 2015).

UN DESA (2014). Partnerships Briefs for Small Island Developing States. Ocean, Seas \& Biodiversity. United Nations Department of Economic and Social Affairs. Available online at: https://sustainabledevelopment.un.org/ content/documents/1349SIDS_BRIEFS_OceansAndSeas.pdf (Accessed July 16, 2015).

UNEP (2014). Emerging Issues for Small Island Developing States. Results of the UNEP UN DESA Foresight Process. Nairobi: United Nations Environment Programme. Available online at: http://www.unep.org/pdf/Emerging_issues_ for_small_island_developing_states.pdf (Accessed July, 16, 2015).

UNEP, UN DESA, and FAO (2012). SIDS-Focused Green Economy: An Analysis of Challenges and Opportunities. Nairobi: United Nations Environment Programme. Available online at: http://www.unep.org/pdf/Green_Economy_ in_SIDS.pdf (Accessed July, 16, 2015).

UN-OHRLLS, UNESCO, and UN-DOALOS (2014). Report of the Expert Group Meeting on the Significance of Marine Science and Technology for SIDS: the Transfer of Marine Technology Transfer to SIDS to Support Sustainable Development, May 14-17, New York, NY. Available online at: http://www.env. gov.sc/images/suppdoc/EGM.report.recommendations.fin.pdf (Accessed July $16,2015)$.

Weeks, R., Pressey, R. L., Wilson, J. R., Knight, M., Horigue, V., Abesamis, R. A., et al. (2014). Ten things to get right for marine conservation planning in the Coral Triangle [version 2; referees: 2 approved]. F1000Res. 3, 91. doi: 10.12688/f1000research.4162

Wilson, D. T., and Mills, C. (2008). "Maximising the benefits of an in-country Foreign Tertiary Education Provider: The School for Field Studies, the Turks and Caicos Islands," in Perspectives on Distance Education - Foreign Providers in the Caribbean: Pillagers or Preceptors? eds S. Marshall, E. Brandon, M. Thomas, A. Kanwar, and T. Lyngra (Vancouver, BC: Commonwealth of Learning), 123-134.

Conflict of Interest Statement: The authors declare that the research was conducted in the absence of any commercial or financial relationships that could be construed as a potential conflict of interest.

Copyright (c) 2015 Hind, Alexander, Green, Kritzer, Sweet, Johnson, Amargós, Smith and Peterson. This is an open-access article distributed under the terms of the Creative Commons Attribution License (CC BY). The use, distribution or reproduction in other forums is permitted, provided the original author(s) or licensor are credited and that the original publication in this journal is cited, in accordance with accepted academic practice. No use, distribution or reproduction is permitted which does not comply with these terms. 